\title{
A zero-cost attention-based approach to promote cleaner streets
}

\author{
Rita Abdel Sater ${ }^{1,2}$, Mathilde Mus ${ }^{1}$, Valentin Wyart $^{1}$, and \\ Coralie Chevallier ${ }^{1}$ \\ ${ }^{1}$ Laboratoire de Neurosciences Cognitives et Computationelles, \\ Département d'Etudes Cognitives, INSERM U960, Ecole \\ Normale Supérieure, PSL Research University, \\ ${ }^{2}$ Departmenet of Economics, Sciences Po, Paris
}

July 2020

\begin{abstract}
In an effort to inform interventions targeting littering behaviour, we estimate how much a change in trash-bag colour increases trash can visibility in Paris. To that end, we apply standard Signal Detection techniques to test how much changing trash-bag colour from grey to red affects subjects' detection rates. In three pre-registered studies (total $\mathrm{N}=922$ ), we find that changing trash bag colour from grey to red translates into a $28 \%$ increase in the perceived number of bins. This means that a zero-cost change of trash-bag colour from grey to red is equivalent to installing 8,400 additional bins in the city of Paris, in terms of perceived density. Replication studies investigating additional colour changes show that changing the colour from grey to either green or blue further increases visibility, with blue exhibiting the highest increase in visibility.
\end{abstract}

\section{Background}

Littering and improper waste disposal in public spaces is an important challenge for communities and local authorities. Maintaining a clean public environment is actually often reported as a top priority in large and touristic cities. In Paris' latest participatory budget poll, Parisians allocated the highest 
number of votes to a project aiming to improve "the living environment through more efficient cleaning of the city" (Maviel, 2018). This has put pressure on the municipality to increase an already sizeable yearly budget of $€ 600$ million devoted to cleaning the city and to maximise the effectiveness of strategies that are already in place to prevent littering behaviour.

Littering is a social problem that not only creates aesthetic damages and exhausts a substantial share of public funds, but it also carries important environmental, physical, and psychological costs (Slaughter et al., 2011; Shenassa, Liebhaber \& Ezeamama, 2006; Ellaway, Macintyre \& Bonnefoy, 2005; Blackman, Harvey, Lawrence \& Simon, 2001). For instance, cigarette butts which are by far the most littered item around the globe - with approximately 15 billion cigarettes improperly discarded in nature every day - are a major source of land and aquatic pollution that can have dramatic toxic effects on entire ecosystems (WHO, 2017; Novotny, Lum, Smith, Wang \& Barnes, 2009; Healton, Cummings, O'Connor \& Novotny, 2011). The presence of litter in the urban environment can also deepen existing economic and health inequalities by depressing local investment or discouraging outdoor physical activity in highly littered neighbourhoods (Blackman et al., 2001; Balfour \& Kaplan, 2002). Experimental evidence also confirms that even small amounts of litter can induce a rise of antisocial behaviours ranging from further degradation of the living environment to more serious crimes, such as theft (Keizer, Lindenberg \& Steg, 2008).

Many empirical studies that have focused on understanding and preventing the widespread prevalence of littering as early as in the 1970s have confirmed that sites with more receptacles tend to have lower littering rates (Geller, Witmer \& Tuso, 1977; Schultz, Bator, Large, Bruni \& Tabanico, 2013; Nkwocha \& Okeoma, 2009; Finnie, 1973). A multilevel analysis identifying the predictors of littering confirmed that about $15 \%$ of littering is due to some aspect of the physical surroundings, such as the presence or absence of waste receptacles and how conveniently placed they are (Schultz et al., 2013). A large increase in the number of trash bins therefore has the potential to trigger notable adjustments in behaviour by removing seemingly small barriers hindering proper waste disposal. In an effort to decrease litter in the streets of Paris, 30,000 bins were deployed by the local authorities in 2013.

However, one issue with this policy is that increasing the number of bins is costly due to the cost of the bin itself, its installation and the added manpower needed to collect trash from additional locations. In Paris, the 30,000 added bins in 2013 cost $€ 2$ million, not including collection costs ${ }^{1}$. Despite

\footnotetext{
${ }^{1}$ Paris : nouveau design pour les poubelles parisiennes. (2013, November
} 
the important effort, this policy was not sufficient to solve the littering problem. Auditing authorities then recommended yet another increase in the number of bins, raising concerns about the congestion of public space (MIE, 2018).

In this study, we test whether an increase in the visual saliency of bins can work as a cost-effective substitute to adding bins by increasing the perceived density of bin availability in a city. This solution appears promising given that cities, in an effort to keep streets charming, tend to deliberately design bins so that they blend with the surrounding urban environment. In Paris, for instance, public trash bins are made of a light gray metal and fitted with discreet grey bags, which means that they are essentially designed to be invisible (Figure 1).

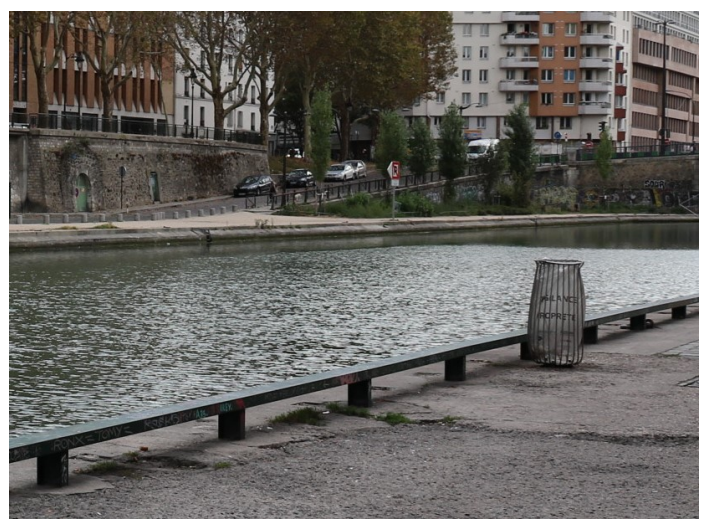

Figure (1) An example of one of the 30,000 trash bins deployed in Paris since 2013, designed to blend in with the urban space

Scientists studying vision have long noted that attention can be modulated in two-ways: endogenously and exogenously. Endogenous attention relies on "top-down", goal-driven mechanisms, leading the individual to voluntarily seek out information in the environment. Exogenous attention is stimulus-driven and refers to processes that automatically lead salient stimuli to attract attention, through "bottom-up" mechanisms. Exogenous attention is also referred to as bottom-up salience and typically emerges from contrast differences between objects and their surroundings; for example, if the colour of an object is particularly salient compared to the background against which it stands. Multiple studies have indeed shown that salient colours elicit rapid and involuntary attention shifts to the object, regardless

27). France Info. Retrieved from https://france3-regions.francetvinfo.fr/paris-ile-defrance/paris/paris-nouveau-design-pour-les-poubelles-parisiennes-366167.html 
of whether subjects had an internally generated (endogenous) motivation to orient their attention to that specific object (Schreij, Theeuwes \& Olivers, 2010).

Interventions in litter control, such as ex-ante campaigns reminding individuals of littering costs or high fines that punish uncivil behaviour ex-post, might increase endogenous attention and trigger top-down visual search to find the closest bin. Interventions aiming at increasing the salience of bins relative to the surroundings will, on the other hand, trigger automatic attentional capture to the bin. Such an intervention could take the form of a simple change of trashbag colour from grey to more salient colours, leading to an increase in the perceived number of bins.

Using a signal detection task applied to modified photographs of Parisian streets, we measure the impact of a simple change in trash-bag colour on bin detection. We then convert the effect to a measure of perceived trash density and approximate the equivalent number of real bins that would have to be added in the streets of Paris to achieve the same effect.

\section{Study 1}

In order to quantify the increase in detectability of trash bins following a change in bag colour from grey to red, a colour that has been reported to be the most salient in a number of vision studies (Gelasca, Tomasic \& Ebrahimi, 2005; Etchebehere \& Fedorovskaya, 2017), we ask participants to detect the presence or absence of a bin in photographs taken in the streets of Paris, with half of them containing a bin and the other half not containing a bin. We then measure the difference in detection accuracy between the two trash bag colour conditions, using Signal Detection Theory parameters.

\section{Methods}

\section{Material}

Photographs. The visibility of a colour signal in a given environment depends greatly on characteristics of that environment such as the background colour, the brightness and amount of ambient illumination (Reynolds, White \& Hilgendorf, 1972). Therefore, in order to ensure comparability between the different conditions (grey-bag condition, red-bag condition, no-bin condition) and eliminate potential biases related to the object's visibility, 50 unique pho- 
tos $^{2}$ in the initial grey bin condition were taken in Parisian streets to span a variety of settings (brightness, contrast, number of distractors, positioning of the bin, etc.). Then, using Adobe Photoshop, we created three versions of each photograph: 1) a grey-bag version with the original photograph of the bin fitted with its original grey bag (grey bag condition) 2) a red-bag version with the same bin edited to be fitted with a red bag (red bag condition) 3) and a no-bin version with the same photograph edited to have no bin (no-bin condition). Figure 2 (Panels a-c) shows an example of the 3 versions of the same photograph.

Questionnaires. We also collected socio-demographic variables (age, sex, income level and educational attainment) and included standard questions used in visual tasks (self-reported colour blindness, self-reported use of glasses or contacts) to assess our sample's representativeness.

\section{Design and procedure}

The pre-registered ${ }^{3}$ experimental task was hosted on the online research platform Prolific Academic and programmed using JavaScript in Qualtrics. Participants were asked to use a full-screen mode on a computer to complete the task, which lasted between 8 and 15 minutes. The same image was seen 4 times by each participant; once in the grey-bag condition, once in the redbag condition and twice in the no-bin condition. Each participant therefore saw 200 photographs, of which 100 contained a trash bin (50 in the red-bag condition and 50 in the grey-bag condition) and 100 in which there was no bin. The 200 trials were split into three blocks separated by two breaks. Both the order of the blocks and the order of pictures within each block were randomised. In each trial, the picture was flashed in the centre of the screen for $700 \mathrm{~ms}$. We used a short display time rather than a display time allowing for visual search because our goal was to focus on automatic and rapid attentional processes (Handy, Kingstone \& Mangun, 1996; Hawkins et al., 1990).

Participants were then asked to indicate whether they saw a bin or not at the end of the trial, using letters on their keyboard. Both responses and reaction times were recorded. In addition, 20 catch trials were included to screen

\footnotetext{
${ }^{2}$ In order to select these 50 photos we first ran a pilot study on 100 participants with a set of 100 photos, only testing the grey condition. This allowed us to calculate a measure of detectability for each photo in the baseline condition and pick photos with discriminabilities that are neither too low or too high. Since the task appeared to be very hard (accuracy of detection was low for many photos), we selected the 50 photos with the highest detection accuracy for the main experiment, and set the display time to $700 \mathrm{~ms}$.

${ }^{3}$ https://osf.io/q7fyd
} 
out participants who were not paying attention during the task. In these trials, participants saw photographs with easily detectable bins that were displayed long enough (1 second) to make the answer trivial. Questionnaire data was collected at the end of the experiment.

Figure (2) Example of a displayed image in the three possible conditions

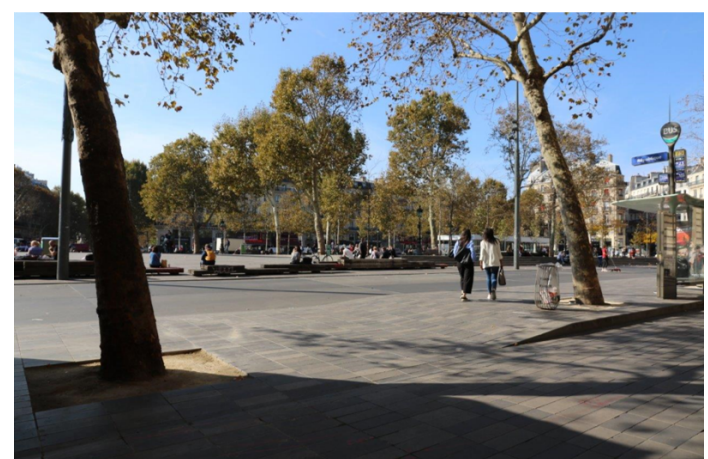

(a) Original image, grey-bag condition

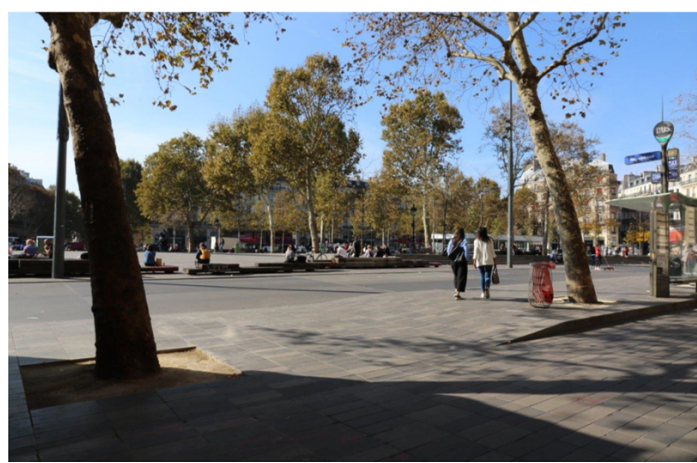

(b) Photoshopped image, red-bag condition

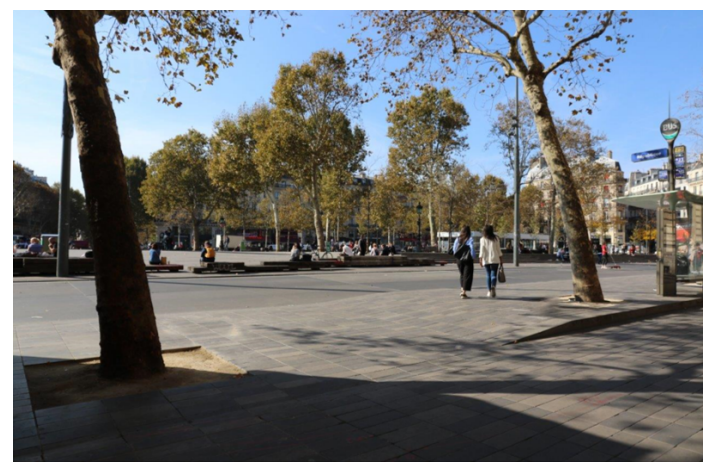

(c) Photoshopped image, no-bin condition

\section{Participants}

Keeping in mind that touristic neighbourhoods in Paris are more littered than non-touristic neighbourhoods, we focused on a non-Parisian sample, i.e. people who are not familiar with the format of bins in Paris. Considering that the highest number of tourists in the city comes from the United Kingdom (Gidrol \& Heim, 2019), we recruited 324 British participants through the online platform Prolific Academic. All participants received a compensation of $£ 7.5$ per hour. We pre-screened participants using Prolific's approval rating; participants with approval ratings below $95 \%$ were screened out. We 
excluded 15 subjects who performed at or below chance in the catch trials ${ }^{4}$. Trials for which reaction times were too short (150 milliseconds or less) or too long (4000 milliseconds or more) were also excluded. After making sure that no participant had more than 30\% missing trials, 309 participants remained in the final analysis (204 females, 104 males, mean age: $36.96+/-12.7$ years), a large enough sample to be detect a minimum effect of $10 \%^{5}$.

\section{Analysis}

Our study's analysis plan relies on Signal Detection Theory in order to quantify the change in salience resulting from a change in bag colour. Signal Detection Theory is used to measure participants' ability to discriminate between a target stimulus and irrelevant noise (Macmillan \& Creelman, 2004).

In Signal Detection Theory, participants' responses are classified into one of the following four categories: hits, misses, false alarms and correct rejections. In the red-bag and grey-bag conditions, a "hit" is recorded when the participant detects the bin and a "miss" is recorded when the participant fails to detect the bin. In the no-bin condition, a "false alarm" is recorded when the participant detects a bin and a "correct reject" is recorded when the participant indicates that there is no bin. In this study, we are particularly interested in capturing changes in bottom-up attention in response to increased trash bag salience. We therefore focus on the discriminability $d^{\prime}$, a metric that allows us to capture earlier stages of visual processing such as the sensory encoding of stimuli.$d^{\prime}$ represents the strength of the signal relative to noise, which corresponds to participants' ability to detect the bin. A discriminability of 0 means that the signal is not distinguished from noise, while higher $d^{\prime}$ values represent a stronger signal-to-noise ratio (i.e. a situation where it is easier for people to discriminate the bin in the scene). $d^{\prime}$ can thus be considered as an index of task difficulty. $d^{\prime}$ is calculated by subtracting $z$ corrected false alarms from hits: $d_{c}^{\prime}=z\left(H_{c}\right)-z\left(F_{c}\right)$ where $\mathrm{H}$ is the hit rate, $\mathrm{F}$ the false alarm rate and the subscript $c$ the colour condition ("red" or "grey") and $z()$ the normal probability curve. The difference between mean discriminability in the two colour conditions $d_{\text {red }}^{\prime}-d_{\text {grey }}^{\prime}$ will thus allow us to quantify the change in bin perception following a change from grey to red. However, participants exhibit a bias in their strategy to set a threshold over which they make the decision that the stimulus is present. This bias is measured by a second metric in Signal Detection Theory, the criterion, or

\footnotetext{
${ }^{4}$ Chance threshold for 20 trials is 14 hits

${ }^{5}$ With 95 confidence level and a power of $80 \%$
} 
'response bias', $c$. It thus reflects a participant's tendency to provide one type of response more frequently than the other. A criterion $c$ with a value of 0 shows that the decision threshold is fixed at a level that generates equivalent rates of false positives and false negatives. $c$ will be positive if there are more hits and false alarms than misses and correct rejections.

Signal Detection Theory thus allows us to get a measure of descriminability $d^{\prime}$ while taking into account the response bias $c$ (Theeuwes \& Van der Burg, 2007; Handy et al., 1996).

\section{Results}

In line with our hypothesis, $d^{\prime}$ is $23 \%$ higher in the red bag condition ( $\mathrm{M}=$ $1.652, \mathrm{SD}=.715)$ than in the grey bag condition $(\mathrm{M}=1.341, \mathrm{SD}=0.622)$, $\mathrm{t}(308)=15.496, p<.001$. Moreover, mean reaction times to detect the bin are lower in the red-bag condition $(\mathrm{M}=107, \mathrm{SD}=283)$ than in the grey-bag condition $(\mathrm{M}=1113.9, \mathrm{SD}=286), \mathrm{t}(308)=-8.8603, p<.001$.

Measuring and taking into account the sample's criterion $c$, we calculated that the observed $d^{\prime}$ increase in the red-bag condition translates into a maximum hit rate change of $28 \%$. Keeping in mind that there are around 30,000 bins in Paris, this result suggests that changing the trash bag colour from grey to red would amount to adding 8,400 bins in the city. Given that the production and installation of one additional bin costs the municipality $€ 150$ (under conservative estimates), achieving with additional bins the same visibility increase as the one obtained by changing the bag from grey to red would cost local authorities around $€ 1,250,550$.

\section{Study 2: Replication study with additional colours}

While the results of the previous study show that red increases bin visibility, we thought it would be interesting to apply the same tool to different colours that have been considered by the municipality of Paris, namely green and blue. It can be noted that green bags were used by the city from 2013 up until 2019 and were then were replaced by grey bags for aesthetic reasons. Blue has been proposed as a possible alternative colour. 
Figure (3) Example of a displayed image in Studies 2.A and 2.B

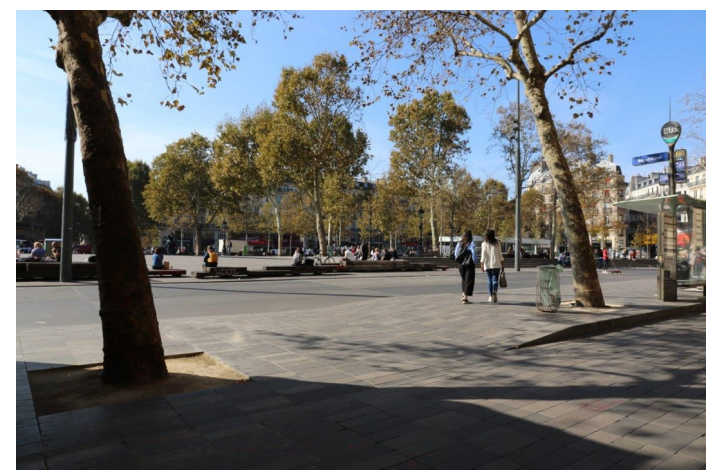

(a) Modified photograph in the green-bag condition

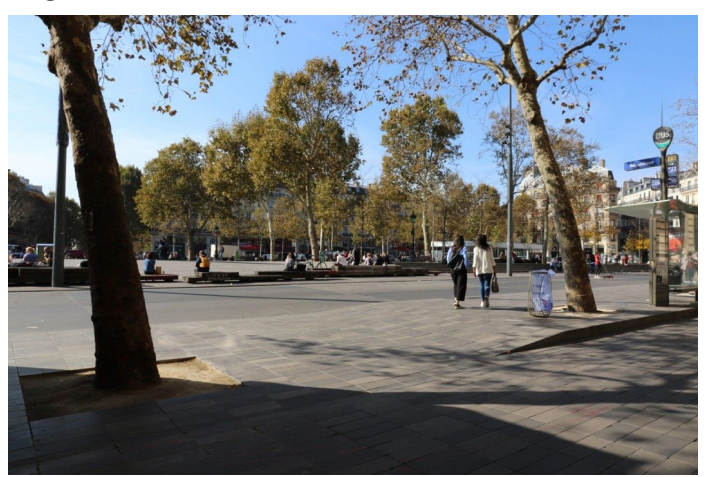

(b) Modified photograph in the blue-bag condition

Using the same experimental methods employed to identify the change in visibility when changing bins from grey to red, study 2 was run to investigate the effect of a change of colour from grey to green on bin visibility (study 2.A) or grey to blue (study 2.B). These two replication studies were preregistered ${ }^{6}$.

\section{Participants}

312 British participants were recruited for Study 2.A and 315 for Study 2.B through the online Platform Prolific Academic and received a compensation of $£ 7.5$ per hour. Participants were pre-screened to have a $95 \%$ or above approval rating. 7 subjects who performed at or below chance in the catch trials were excluded from the analyses of each study. Trials for which reaction times were too short (150 milliseconds or less) or too long (4000 milliseconds or more) were also excluded. After making sure that no participant had more than 30\% missing trials, 305 participants remained in the final analysis for Study 2.A (175 females, 130 males, mean age: $35.7+/-12.2$ years) and 308 (202 females, 106 males, mean age: $36.7+/-12.3$ years).

\section{Results}

$d^{\prime}$ is $24 \%$ higher in the green-bag condition (Study 2.A) $(\mathrm{M}=1.7155$, SD $=.71)$ than the one observed in the grey-bag condition $(\mathrm{M}=1.341, \mathrm{SD}=$ $0.6), \mathrm{t}(305)=6.1454, p<.001$. Maximum hit rate calculations suggest that this change in d' corresponds to an increase in the visibility rate by $30 \%$, equivalent to installing 9,000 grey bins in the city of Paris. This would have

\footnotetext{
${ }^{6}$ https://osf.io/48cs3
} 
cost the local authorities $€ 1,350,000$. Study $2 . \mathrm{B}(\mathrm{N}=308)$ tests the visibility of the blue-bag condition and shows the highest increase in discriminability compared to grey out of the three tested colours; in the blue-bag condition, $d^{\prime}$ is $34 \%$ higher $(\mathrm{M}=1.859, \mathrm{SD}=.707)$ than the one in the grey bag condition $(\mathrm{M}=1.384, \mathrm{SD}=0.62), \mathrm{t}(305)=8.818, p<.001$. This translates into an increase of $46 \%$ of trash can visibility, similar to the addition of 13,800 new bins, avoiding a cost amounting to $€ 2,070,000$. Figure 4 summarises the results from the three Studies.

Figure (4) Results of study 1 and replicated studies 2.A and 2.B.

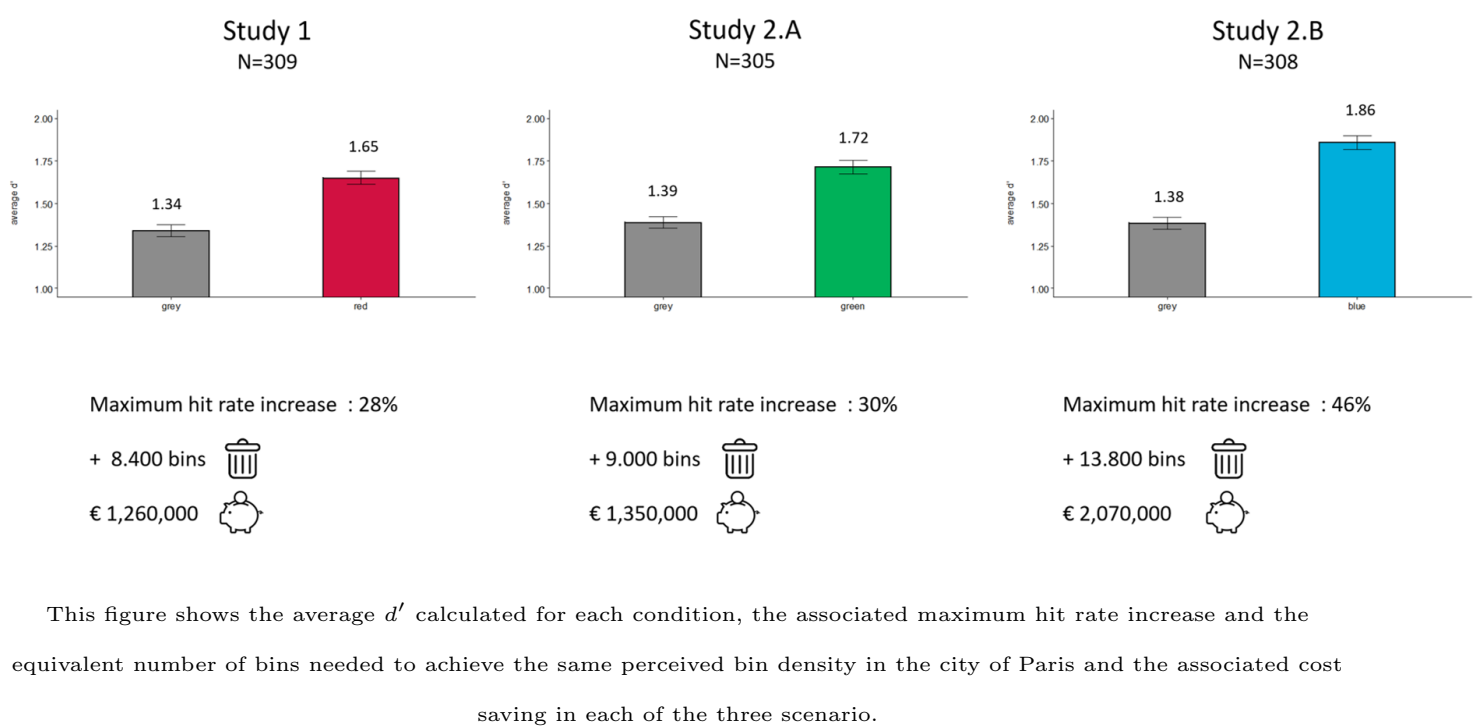

\section{General discussion}

Individuals are often meaningfully influenced by modifications in their environment, even ones that appear as minor. One of the main propositions put forward in nudge theory is the importance of alterations to the physical environment, in order to align behaviour with individual and social goals (Thaler \& Sunstein, 2009). Understanding how to enhance the visibility of waste bins therefore has the potential to ultimately favour better anti-littering policies with low-cost nudges.

The results of this study suggest that a mere change in the colour of bins can result in a cost-effective intervention that would increase their perceived density in an urban setting; a change of bag colour from grey to red, green or 
blue in the city of Paris is equivalent to installing $8,400,9,000$ or 13,800 additional bins respectively. This has important implications for policy-making: while changing the colour of bags is a zero-cost intervention, adding new bins in order to achieve the same visibility can cost Parisian authorities up to $€ 2,070,000$ in installation and maintenance costs. Beyond the sizeable monetary costs, changing the colour of bin bags as opposed to increasing their number avoids overcrowding an already congested public space.

These low-cost context design interventions that elicit involuntary attention to the bin in a given environment could be a more effective behavioural strategy to discourage littering than a mere and usually costly increase in the number of bins. This means that, when evaluating interventions that increase the availability of bins in a city, it might be more relevant to tackle perceived density, rather than actual density.

This result provides ground for future work investigating whether increased visibility of bins has a down-the-road impact on littering behaviour. Previous results suggest that this is quite plausible. For example, it was shown that littering rates in a shopping mall were $40 \%$ lower around highly noticeable and beautiful trash bins than around unobtrusive ones (Geller, Brasted \& Mann, 1980). In another experiment, a decrease in improper cigarette butt disposal was observed outside a university campus after replacing normal ashtrays by ones that were decorated and eye-catching (Cope, Huffman, Allred \& Grossnickle, 1993). Making trash containers more attractive or noticeable has been tested as an alternative to adding bins (Arnold, 2015; Geller et al., 1980; O'Neill, Blanck \& Joyner, 1980). Some cities, like Copenhagen and Vienna, have opted for increased salience of bins and have recorded drastic positive results (MIE, 2018).

More generally, this paper is a telling illustration of how laboratory studies can provide insightful contributions to policy-making and constitute a first crucial step before conducting field experiments. Indeed, if a policy maker wants to increase the perceived density of bins, it would be highly inefficient to go straight to a costly field trial comparing various bin colours. Similarly, it would be highly inefficient to rely only on intuitions. As a matter of fact, we asked a sample of 150 people on the platform Prolific to provide their intuition on this question: "Imagine you are in charge of making sure that bins in your city are highly visible. Which colour would you pick for the bins? Green, red or blue?". Strikingly, the most common answer was red ( $50 \%$ ), while it was shown to be the colour that is the least efficient in improving detectability in our studies. Determining which colour is most likely to be salient in the lab can therefore be a crucial first step before elaborating a field strategy.

The method we used can be easily taken up by policy makers in or- 
der to produce evidence-based decisions on how to increase the visibility of trash receptacles in urban settings. Based on insights obtained in a lab setting, decision-makers can then maximise the efficiency of a field intervention, evaluated with rigorous but often costly randomised controlled trials. For instance, our method could be replicated with a variety of bin shapes and colours to help identify the most effective choice before turning to large scale implementation or field trials. Well-designed lab research can provide crucial insight for policy and is often complementary to field research, but is still greatly underused in the domain of policy development (Lunn \& Choisdealbha, 2018).

The findings of this experiment are subject to a number of limitations that should be mentioned. Firstly, we focused on a non-Parisian sample to avoid participants who are already familiar with the design of Paris bins and who would be less representative of the population passing through the most highly touristic and highly littered Parisian neighbourhoods. This means that our sample is not representative of the entire population of people who visit and live in Paris. Although this does not affect the internal validity of our analysis, a sampling that better represents the population of passersby in a given city might lead to more tailored results. Secondly, while this task allows to measure the effect of a change in colour on the salience and thus perceived density of bins in the city, it does not say anything about the effect this nudge would have on real-life behaviour.

\section{Acknowledgement}

This study was supported by the Institut d'Etudes Cognitives (ANR-10IDEX-0001-02 FrontCog), the Institut national de la santé et de la recherche médicale (INSERM). It was also made possible by the support and funding of the Paris City Hall Green Spaces and Environment Department (DEVE). We gratefully thank Arnaud Le Bel Hermile and Mariane Lavallée (Acteurs du Paris durable) for their support and insight throughout this study.

\section{References}

Arnold, M. (2015). The relationship between receptacle design, normative conduct, environmental concerns, and recycling behavior.

Balfour, J. L. \& Kaplan, G. A. (2002). Neighborhood environment and loss of physical function in older adults: Evidence from the alameda county study. American Journal of Epidemiology, 155(6), 507-515. 
Blackman, T., Harvey, J., Lawrence, M. \& Simon, A. (2001). Neighbourhood renewal and health: Evidence from a local case study. Health $\&$ place, 7(2), 93-103.

Cope, J. G., Huffman, K. T., Allred, L. J. \& Grossnickle, W. F. (1993). Behavioral strategies to reduce cigarette litter. Journal of Social Behavior and Personality, 8(4), 607.

Ellaway, A., Macintyre, S. \& Bonnefoy, X. (2005). Graffiti, greenery, and obesity in adults: Secondary analysis of european cross sectional survey. BMJ, 331 (7517), 611-612. doi:10.1136/bmj.38575.664549.F7

Etchebehere, S. \& Fedorovskaya, E. (2017). On the role of color in visual saliency. Electronic Imaging, 2017(14), 58-63.

Finnie, W. C. (1973). Field experiments in litter control. Environment and behavior, 5(2), 123-144.

Gelasca, E. D., Tomasic, D. \& Ebrahimi, T. (2005). Which colors best catch your eyes: A subjective study of color saliency. In Fisrt international workshop on video processing and quality metrics for consumer electronics. Citeseer.

Geller, E. S., Brasted, W. \& Mann, M. (1980). Waste receptacle designs as interventions for litter control. Journal of Environmental Systems, 9, $145-160$.

Geller, E. S., Witmer, J. F. \& Tuso, M. A. (1977). Environmental interventions for litter control. Journal of Applied Psychology, 62(3), 344.

Gidrol, J.-C. \& Heim, V. (2019). Les hébergements collectifs touristiques en 2018. une fréquentation dynamique tirée par la clientèle non résidente.

Handy, T. C., Kingstone, A. \& Mangun, G. R. (1996). Spatial distribution of visual attention: Perceptual sensitivity and response latency. Perception $\&$ Psychophysics, 58(4), 613-627.

Hawkins, H. L., Hillyard, S. A., Luck, S. J., Mouloua, M., Downing, C. J. \& Woodward, D. P. (1990). Visual attention modulates signal detectability. Journal of Experimental Psychology: Human Perception and Performance, 16(4), 802.

Healton, C. G., Cummings, K. M., O'Connor, R. J. \& Novotny, T. E. (2011). Butt really? the environmental impact of cigarettes. Tobacco Control, 20 (Suppl 1), i1-i1.

Keizer, K., Lindenberg, S. \& Steg, L. (2008). The spreading of disorder. Science, 322(5908), 1681-1685.

Lunn, P. D. \& Choisdealbha, Á. N. (2018). The case for laboratory experiments in behavioural public policy. Behavioural Public Policy, 2(1), $22-40$.

Macmillan, N. A. \& Creelman, C. D. (2004). Detection theory: A user's guide. Psychology press. 
Maviel, N. (2018). Budget participatif : 211000 parisiens ont voté cette année. Le Parisien. Retrieved from http://www.leparisien.fr/paris-75/budgetparticipatif - 211 - 000 - parisiens - ont - vote - cette - annee - 02 - 10 - 2018 7909005.php

MIE. (2018). La politique parisienne en matière de propreté. Le Conseil de Paris, Mairie de Paris.

Nkwocha, E. E. \& Okeoma, I. O. (2009). Street littering in nigerian towns: Towards framework for sustainable urban cleanliness. African research review, 3(5).

Novotny, T., Lum, K., Smith, E., Wang, V. \& Barnes, R. (2009). Cigarettes butts and the case for an environmental policy on hazardous cigarette waste. International journal of environmental research and public health, 6(5), 1691-1705.

O’Neill, G. W., Blanck, L. S. \& Joyner, M. A. (1980). The use of stimulus control over littering in a natural setting. Journal of applied Behavior analysis, 13(2), 379-381.

Reynolds, R. E., White, R. M. \& Hilgendorf, R. L. (1972). Detection and recognition of colored signal lights. Human Factors, 14 (3), 227-236.

Schreij, D., Theeuwes, J. \& Olivers, C. N. (2010). Abrupt onsets capture attention independent of top-down control settings ii: Additivity is no evidence for filtering. Attention, Perception, \&6 Psychophysics, 72(3), 672-682.

Schultz, P. W., Bator, R. J., Large, L. B., Bruni, C. M. \& Tabanico, J. J. (2013). Littering in context: Personal and environmental predictors of littering behavior. Environment and Behavior, 45(1), 35-59.

Shenassa, E. D., Liebhaber, A. \& Ezeamama, A. (2006). Perceived Safety of Area of Residence and Exercise: A Pan-European Study. American Journal of Epidemiology, 163(11), 1012-1017. doi:10.1093/aje/kwj142. eprint: http://oup.prod.sis.lan/aje/article-pdf/163/11/1012/401897/ kwj142.pdf

Slaughter, E., Gersberg, R. M., Watanabe, K., Rudolph, J., Stransky, C. \& Novotny, T. E. (2011). Toxicity of cigarette butts, and their chemical components, to marine and freshwater fish. Tobacco control, 20 (Suppl 1), i25-i29.

Thaler, R. H. \& Sunstein, C. R. (2009). Nudge: Improving decisions about health, wealth, and happiness. Penguin.

Theeuwes, J. \& Van der Burg, E. (2007). The role of spatial and nonspatial information in visual selection. Journal of Experimental Psychology: Human Perception and Performance, 33(6), 1335.

WHO. (2017). Tobacco and its environmental impact: An overview. 